\title{
CHITOSAN COMPOSITES PREPARATION AND CHARACTERIZATION OF GUIDE TUBES FOR NERVE REPAIR
}

\author{
GALO CÁRDENAS-TRIVIÑO ${ }^{a^{*}}$ AND RODRIGO SOTO-SEGUEL ${ }^{b}$ \\ ${ }^{a}$ Facultad de Ingeniería, DIMAD, Escuela de Ingeniería Química, Universidad del Bío-Bío, Avda I. Collao 1202, Concepción, Chile. \\ ${ }^{b}$ Universidad de Concepción, Facultad de Química, Edmundo Larenas 126, Concepción, Chile.
}

\begin{abstract}
Nerve regeneration is a biologically complex phenomenon. Once the nervous system is damaged, its recovery is difficult and causes a malfunction in other parts of the body that can occur because mature neurons do not suffer cell division. To increase the prospects of axonal regeneration and functional recovery, research has focused on the construction and design of nerve conduction channels or guide tubes. That is why a high molecular weight chitosan was used as a starting material, which was first characterized by the following analyses: moisture, ash, FTIR, TGA, total nitrogen determination, viscosity for the determination of the average molecular weight and degree of deacetylation by potentiometric titration. Once the starting chitosan is characterized, tube-shaped biomaterials are prepared based on a $4 \% \mathrm{w} / \mathrm{v}$ chitosan solution, using $\mathrm{CH}_{3} \mathrm{COOH}$ solvent at $1 \% \mathrm{v} / \mathrm{v}$. Calcium glutamate is added to $0.5 \%$ and $1 \% \mathrm{w} / \mathrm{v}$, neutralizing with $\mathrm{NaOH} 0.25 \mathrm{~N}$, and then taken to the molds to be frozen and subsequently freeze-dried. Finally, the materials are coated with polylactic acid, in order to achieve a strengthening in the structure of the material. These materials are also prepared in a bio clean area. The different materials are chemically and morphologically characterized by FTIR, TGA, Atomic Absorption Spectroscopy, Mechanical Properties, Morphology and solubility test.
\end{abstract}

Keywords: Neuronal tubes, chitosan, calcium glutamate, polylactic acid, freeze- dried.

\section{INTRODUCTION}

Anatomically the central nervous system is divided into: central nervous system and peripheral nervous system. The peripheral nervous system includes cranial and peripheral nerves, the nodes associated with cranial and spinal nerves, and peripheral receptor organs [1].

A peripheral nerve is composed of nerve fibers (axons) that can vary in size and caliber, and its function is to transmit impulses in the afferent or efferent direction to the central nervous system. Peripheral nerves are often referred to as mixed nerves because they are composed of both sensitive fibers and motor fibers. The structural organization of the nerve changes along it by the repeated division and union of different nerve fascicles, producing complex fascicular formations. A peripheral nerve may be composed of thousands of axons, but the number of them on each peripheral nerve is variable [1,2].

The transection of the axon (axotomy) represents a powerful paradigm for studying cell regeneration and death in neurons. Depending on where the injury is carried out, axonal damage allows neurons to regenerate their axons, restore their functional contact with their target cells, or to start a complex process that leads to neuronal death $[3,4]$.

It is recognized that axonal degeneration is a major cause of disease, and that pathogenic mechanisms have not yet been well identified [5, 6]. Damage of a peripheral nerve in mammals induces a complex but reproducible sequence of histopathological events. After the section of a nerve, the first response happens at the distal end of nerve fibers, this phenomenon is called anrograde degeneration (wallerian degeneration) [7,8]; then manifests, in the proximal fibers of the lesion, the phenomenon known as retrograde neuronal degeneration [9-11]; in the cell soma occur progressive degenerative changes that lead to neuronal death $[11,12]$.

The ability of peripheral nerves to regenerate contrasts with the inability of the central nervous system. This regenerative skill of the peripheral nervous system has been attributed to the micro-environment provided by the Schwann cells of the distal nervous stump. Despite regenerative capacity, functional recovery of a damaged peripheral nerve is still disappointing, even after immediately applying microsurgery to repair the nerve. Clinical experience has established that functional recovery is particularly bad for damage to large nerves, such as those that arise from the lumbar plexus, as they need to travel long distances to restore connections with their target cells, which have been denerved by the damage. The slow pace of regeneration, $1-3 \mathrm{~mm} / \mathrm{day}$, can take months or even years [13, 14].
The functionality of peripheral nerve regeneration depends on interactions between regeneration axons, non-neural cells, growth factors and their receptors, adhesion cell molecules and extracellular matrix materials [9]. The regeneration of the peripheral nerve includes the formation of axonic shoots, projection of the regenerated axon and, finally, reinervation to target tissue (terminal plate formation); however, the factors that control the regeneration of peripheral nerves are unknown [15-20].

Injured peripheral nerve repair is not a recent concept, there are reports of nerve repairs dating back to 1836 . Among the surgical techniques used for nerve repair are the neuroraphy, the repair technique most used in both the human and animal clinic, consists in the approximation of the nerves injured by sutures, but which does not lead to a complete functional recovery of the nerve. As an alternative to this technique and with favorable functional prognosis, tubulization is used. This system consists of joining defects in the continuity of a sectioned nerve and/or that have lost a segment, to direct the regenerative process, maintaining a chemical communication between the proximal and distal stump [16].

Due to the lack of suitable materials to manufacture useful prostheses in nerve repair, researchers have sought new alternatives and are now using organic materials that allow their biodegradation and bio absorption by the body, thus avoiding a second surgery to remove them, as was the case with silicone prostheses.

To make these tubes are used natural or synthetic materials and they must gather certain qualities such as, a wall and a porous channel, be biodegradable, have the ability to release bioactive factors, incorporate cells and an orientation matrix that supports their migration without collapsing and also serve as a guidance substrate for a nerve in regeneration without intervening with the regeneration itself [17].

In tissue engineering there is a need to create biomaterials (synthetic, natural or modified natural material) intended to be in contact and interact with a biological system effective that can be used as grafts for a wide variety of biomedical applications. An important aspect in the application of biomaterials is that they must be biocompatible.

In the field of biomaterials of natural and degradable origin, chitosan appears. Chitosan is a polymerized carbohydrate derived from chitin, a linearly structured polysaccharide found in the exoskeleton of crustaceans, derived from chitin. Chitin is the second most abundant biopolymer found in nature, and perhaps the lesser known (the first is cellulose) is a waste product of the marine food industry [19].

*Corresponding author email: gcardenas@ubiobio.cl 


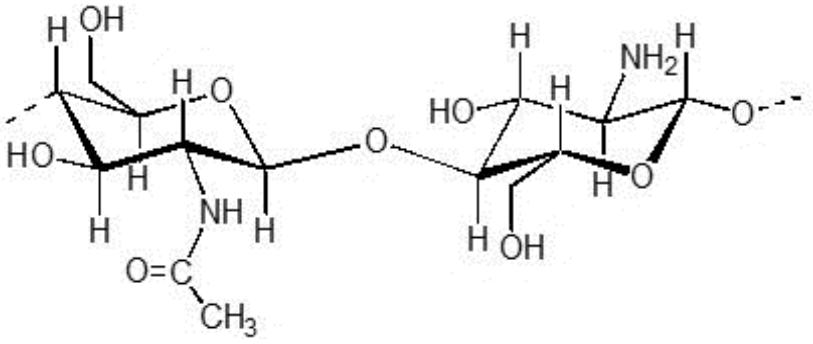

Figure 1. Chitosan structure

It has favorable physical properties, which allows us to use it in different forms, maintaining its structure and flexibility. Due to its physical, chemical and biological characteristics, chitosan is a biomaterial of biomedical application and can easily be processed to sutures, wound protectors, grafts, membranes, capsules, porous sheets, tubes, microspheres among others.

This work is based on obtaining guide tubes, mainly based on the combination of two important elements: on the one hand the use of an excitatory neurotransmitter, Calcium Glutamate (Glu. Ca), which favors the synapse thus allowing communication between nerve cells, preloaded to the matrix of a biomaterial such as Chitosan (Cs), which will eventually be made a coating with Polylactic Acid (PLA) in order to avoid one of the biggest drawbacks presented by these materials, such as the loss of its structure due to the great solubility that presents in biologically by doing that over time.

\section{EXPERIMENTAL}

I. The chitosan and composites were characterized by the following techniques.

\section{Humidity Percentage Chitosan}

It consists of massing approximately $0.5 \mathrm{~g}$ of chitosan and then is dried in stove at $105^{\circ} \mathrm{C}$ for $24 \mathrm{~h}$. It is then left in desiccator for $30 \mathrm{~min}$ and the residue is massed where by mass difference the percentage of moisture is obtained.

\section{Percentage of Ashes Chitosan}

It consists of massing approximately $0,1 \mathrm{~g}$ of chitosan which is left in a crucible and then charred in muffle furnace at $900^{\circ} \mathrm{C}$ for $6 \mathrm{~h}$. Finally, left in desiccator for $30 \mathrm{~min}$ and then massed to obtain by difference the percentage of ash.

\section{Total Nitrogen Determination}

It is determined by the Kjeldhal method, in which between $0.0060-0.0080$ grams of chitosan are massed and placed in a Kjeldhal tube. Then a catalyst spatula tip ( $\mathrm{HgO} 2.4 \%$ and $\left.\mathrm{K}_{2} \mathrm{SO}_{4} 97.6 \%\right)$ is added and $1 \mathrm{~mL} \mathrm{H}_{2} \mathrm{SO}_{4}$ concentrate and the sample is left in the heater until total discoloration. Subsequently in flask of $125 \mathrm{~mL} 10 \mathrm{~mL}$ of boric acid $4 \%$ and 5 drops of indicator are added. Finally, the sample is added, washed at least 2 times with distilled water, $5 \mathrm{~mL} \mathrm{NaOH} 5$ $\mathrm{M}$ are added and when at least $50 \mathrm{~mL}$ are received in the $125 \mathrm{~mL}$ flask is left to cool and is tipped with $\mathrm{HCl} 0.015 \mathrm{~N}$.

\section{Determination of the degree of deacetylation}

It consists of a potentiometric titration where a $250 \mathrm{~mL}$ beaker is added between 0.10 to $0.12 \mathrm{~g}$ of chitosan, then $25 \mathrm{~mL}$ of $\mathrm{HCl} 0.2 \mathrm{~N}$ is added under agitation and finally tipped with $\mathrm{NaOH} 0.1 \mathrm{~N}$.

\section{Viscosity and average molecular weight}

Approximately $1 \mathrm{~g}$ of chitosan is massed, then transferred to a $100 \mathrm{~mL}$ beaker and added $100 \mathrm{~mL}$ of $\mathrm{CH}_{3} \mathrm{COOH}$ to $1 \% \mathrm{v} / \mathrm{v}$. The solution is left in agitation for a time of 2 hours until complete homogenization, and then filtered. Finally, its viscosity is measured on the DV-I Prime Brookfield LV viscometer.

\section{Fourier Transform Infrared Spectroscopy (FTIR)}

The FT-IR Nicolet Magna 550 equipment is used, where 1\% pickups are prepared in $\mathrm{KBr}$ and FTIRs are worked on OMNIC software.

\section{Thermogravimetric Analysis (TGA)}

This analysis allows to observe the behavior of the sample at different temperatures, for this we work with the equipment STA 625 , where $5-10 \mathrm{mg}$ of chitosan is subjected to a gradual heating from 25 to $600^{\circ} \mathrm{C}$, with a heating rate of $20^{\circ} \mathrm{C} / \mathrm{min}$.

\section{Preparation of tube-shaped biomaterials}

A Chitosan (Cs) solution at $4 \%$ w/v was used, using different percentages of Calcium glutamate (Glu.Ca) as an additive, in order to obtain after the freezing and freeze-drying process the biomaterials, which were eventually coated with polylactic acid (PLA).

Table 1. Samples of Prepared Materials.

\begin{tabular}{|c|l|}
\hline Samples & \multicolumn{1}{|c|}{ Materials } \\
\hline 1 & Cs $4 \%$ \\
\hline 2 & Cs $4 \%+$ Glu. Ca $0.5 \%$ \\
\hline 3 & Cs $4 \%+$ Glu. Ca $0.5 \%+$ PLA $1 \%$ \\
\hline 4 & Cs $4 \%+$ Glu. Ca $0.5 \%+$ PLA $2 \%$ \\
\hline 5 & Cs $4 \%+$ Glu. Ca $1 \%$ \\
\hline 6 & Cs $4 \%+$ Glu. Ca $1 \%+$ PLA $1 \%$ \\
\hline 7 & Cs $4 \%+$ Glu. Ca $1 \%+$ PLA $2 \%$ \\
\hline
\end{tabular}

To obtain these tube-shaped materials, a $4 \% \mathrm{w} / \mathrm{v} \mathrm{CH}_{3} \mathrm{COOH}$ solution at $1 \%$ $\mathrm{v} / \mathrm{v}$ is started by preparing a chitosan solution. Once homogenized, the solution is filtered in order to remove any impurities it may contain. Once the solution is obtained, it is neutralized with $\mathrm{NaOH} 0.25 \mathrm{~N}$ until it reaches $\mathrm{pH} 6$ and then the necessary amount of additive is added, corresponding to the material to be obtained. This solution is brought to the molds to give it the required dimensions of a tube (length $4 \mathrm{~cm}$ and internal diameter of approximately $4 \mathrm{~mm}$ ), and then frozen by a prolonged period of $12 \mathrm{~h}$ at $-62^{\circ} \mathrm{C}$. The frozen samples are freezedried for 3 days, obtaining the desired tubes. Once the tubes are obtained they are coated with Polylactic acid at 1 and $2 \% \mathrm{w} / \mathrm{v}$ respectively and the materials are vacuum-dried at $25^{\circ} \mathrm{C}$. This same methodology was considered, to prepare tube-shaped biomaterials inside the bio-clean area.

\section{Characterization of prepared biomaterials.}

Characterize biomaterials prepared both chemically and morphologically using techniques such as FTIR, TGA (described above), Morphology (SEM), Solubility Test, Determination of calcium by Atomic Absorption Spectroscopy and Mechanical Properties.

\section{Morphology, Scanning Electron Microscopy (SEM)}

This technique allows to see the size and quantity of pores present in the materials. To do this, the samples are frozen in liquid nitrogen for 5 minutes, then fractured, if preventing the pores from being damaged as little as possible. Finally, the surface to be analyzed is metallized with gold and then observed through the microscope.

\section{Solubility test}

For this test a part of the tube is cut, then massed and left in $10 \mathrm{ml}$ of $70 \% \mathrm{v} / \mathrm{v}$ ethanol solution for a time of $24 \mathrm{~h}$. The ethanol is then thrown away and washed with nanopure water. The sample is then left in $20 \mathrm{ml}$ of $0.9 \% \mathrm{w} / \mathrm{v}$ physiological serum for $24 \mathrm{~h}$. Finished this is filtered and dried on stove for $3 \mathrm{~h}$ at $40^{\circ} \mathrm{C}$. Finally, it is massed and by mass difference the percentage of solubilized material is calculated.

\section{Atomic Absorption Spectroscopy}

First a part of the tubes is sectioned and left in liquid nitrogen, in order to be able to crush these materials and grind them, which are then dried in stove at $45^{\circ} \mathrm{C}$. Subsequently around $50 \mathrm{mg}$ of sample is massed and left in porcelain crucibles and brought to the muffle furnace to calcin them for a time of $5 \mathrm{~h}$ and 
at a temperature of $500^{\circ} \mathrm{C}$. After the calcining process the crucibles are removed and treated with $1 \mathrm{~mL}$ of $\mathrm{HCl} 4 \mathrm{~N}$ and then filtered by paper leaving them in a 50 $\mathrm{mL}$ graduated flask and completed by volume with nanopure water. Then the calibration curve was built for this, the calcium standards of 1, 2, 3, 4 and $5 \mathrm{mg} / \mathrm{L}$ were prepared, where each standard was added lanthanum and $\mathrm{KCl}$ and worked at a wavelength of $422 \mathrm{~nm}$. Finally, samples are measured.

\section{Mechanical Properties}

Many materials when in service are subject to forces or loads. In such conditions it is necessary to know the characteristics of the material to design the instrument where it will be used in such a way that the efforts to which it will be subjected are not excessive and the material is not fractured. These materials were subjected to compression tests where SANS equipment, model CMT 2502, consisting of a fixed and a movable arm, whose samples used had a diameter of $8 \mathrm{~mm}$ and a length of $16 \mathrm{~mm}$.

\section{RESULTS AND DISCUSSION}

\section{Characterization of chitosan}

1. Table 2. Results of the characterization of Chitosan.

\begin{tabular}{|c|c|c|c|c|}
\hline Humidity & Ashes & $\begin{array}{c}\text { Viscosimetric } \\
\text { Molecular Weight }\end{array}$ & $\begin{array}{c}\text { Total } \\
\text { nitrogen }\end{array}$ & $\begin{array}{c}\text { Degree of } \\
\text { Acetylation }\end{array}$ \\
\hline $12 \pm 0.5 \%$ & $0.5 \pm 0.1 \%$ & $319.500 \pm 100 \mathrm{~g} / \mathrm{mol}$ & $7.5 \pm 0.1 \%$ & $15 \pm 1 \%$ \\
\hline
\end{tabular}

\section{FTIR}

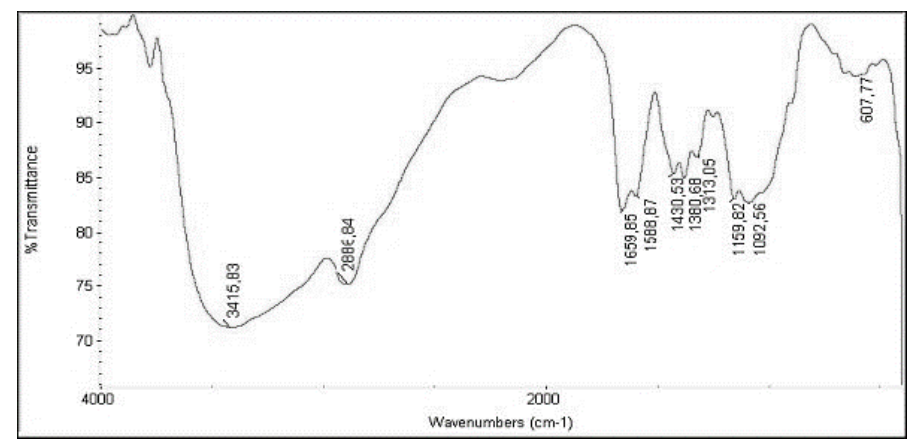

Figure 3. FTIR spectra of chitosan.

Table 3. Main Bands of the Chitosan

\begin{tabular}{|c|c|c|}
\hline Characteristic Band & Range $\left.\mathbf{( c m}^{-\mathbf{1}}\right)$ & Vibration Type \\
\hline -OH group & 3415 & Stretching \\
\hline -CH group & 2886 & Tension \\
\hline Amide I & 1659 & Axial deformation $\mathrm{C}=\mathrm{O}$ \\
\hline $\mathrm{NH}_{2}$ group & 1588 & Torque $-\mathrm{NH}_{2}$ \\
\hline $\mathrm{CH}_{3}$ group & 1430 & Deformation \\
\hline Amide III & 1380 & Axial deformation \\
\hline -C-O-C- group & $1159-1092$ & Antisymetric tension \\
\hline
\end{tabular}

\section{Thermal study of the starting chitosan (TGA).}

Figure 4 shows that at $12.6^{\circ} \mathrm{C}$ the sample was very wet not presenting decomposition, at $124^{\circ} \mathrm{C}$ there is a loss of $9.2 \%$ of the initial mass due to the loss of moisture of the material. The significant mass loss that begins at $236^{\circ} \mathrm{C}$ corresponds to processes of depolymerization and decomposition of the different acetyl and amino groups of the chitosan.

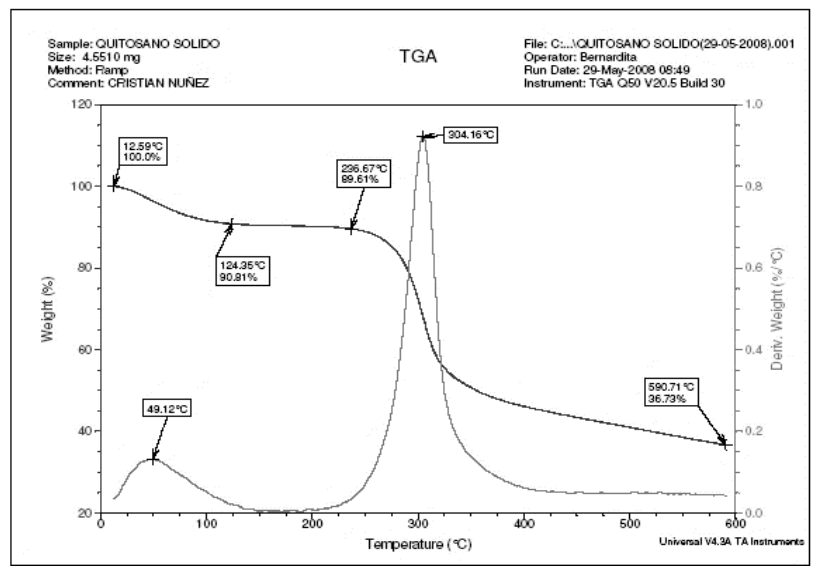

Figure 4. Chitosan thermogram.

II. Characterization of the additive Calcium Glutamate and Polylactic Acid.

Both Calcium Glutamate and Polylactic Acid were characterized by infrared spectroscopy and thermogravimetric analysis.

\section{FTIR Calcium Glutamate.}

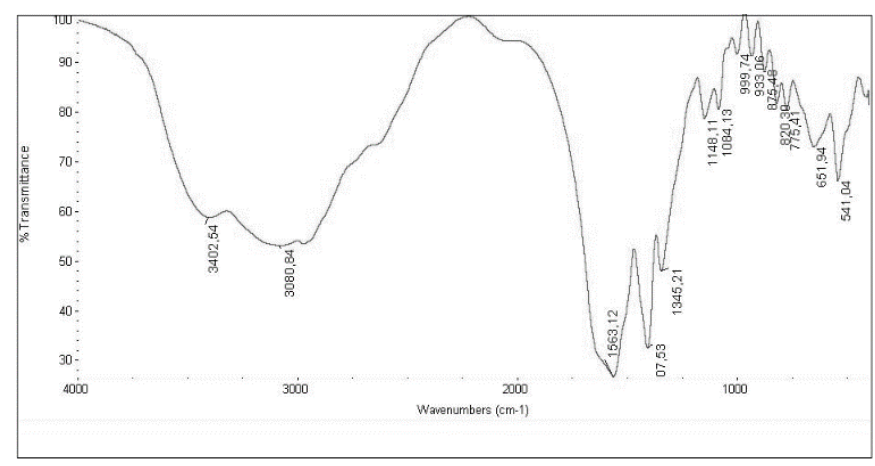

Figure 5. FTIR Spectrum Calcium Glutamate.

Table 4. Main bands of Calcium Glutamate.

\begin{tabular}{|c|c|c|}
\hline Characteristic Band & Range $\left(\mathbf{c m}^{-\mathbf{1}}\right)$ & Vibration Type \\
\hline$-\mathrm{OH} ;-\mathrm{NH}_{2}$ & $3400-3080$ & Tension vibrations \\
\hline $\mathrm{NH}_{2}$ Primary & 1563 & Deformation vibrations \\
\hline $\mathrm{NH}_{2}$ Primary & $820-775$ & Deformation vibrations \\
\hline$\left(\mathrm{COO}^{-}\right)$ & 1407 & Asymetric deformation vibrations \\
\hline
\end{tabular}

\section{Calcium Glutamate TGA}

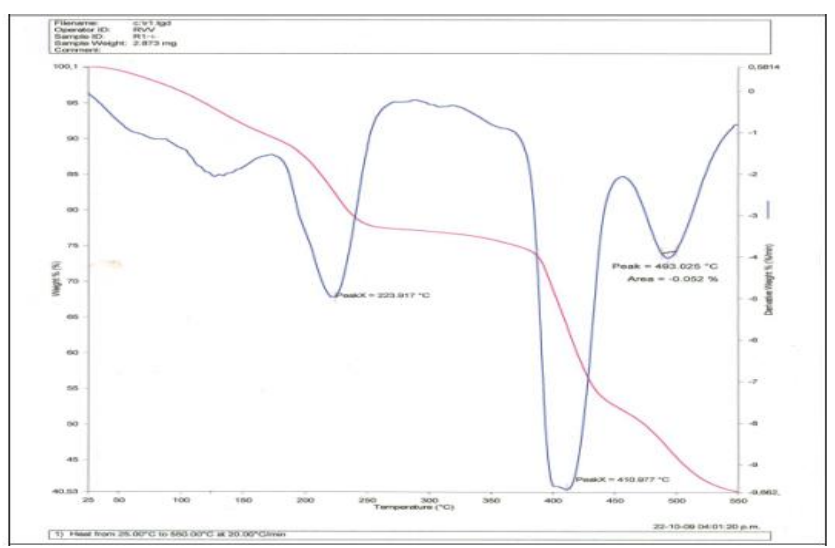

Figure 6. TGA of Glu. Ca 


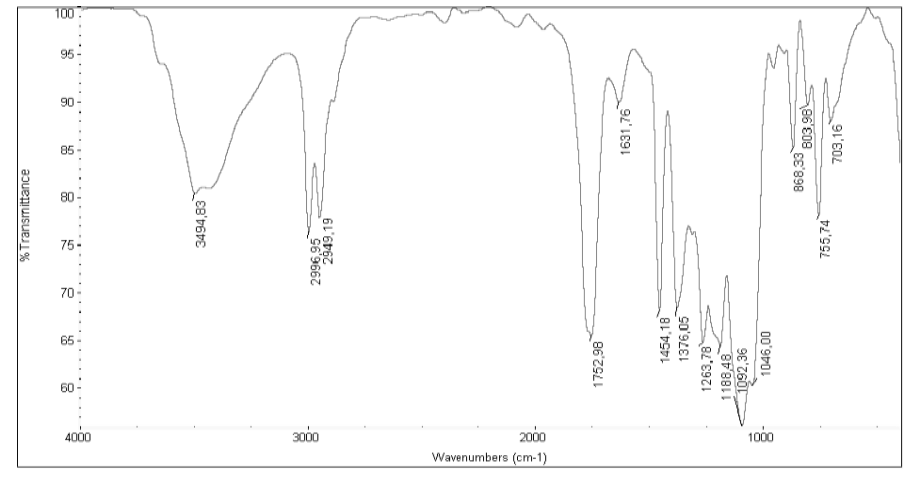

Figure 7. FTIR spectra PLA.

Table 5. Bands of Polylactic Acid

\begin{tabular}{|c|c|c|}
\hline Characteristic Band & Range $\mathbf{( c m}^{-\mathbf{1}} \mathbf{)}$ & Vibration Type \\
\hline $\mathrm{C}-\mathrm{H}$ & 2990 & Tension vibration \\
\hline $\mathrm{C}=\mathrm{O}$ ester carbonyl & 1752 & Tension vibration \\
\hline $\mathrm{CH}_{3} \mathrm{C}-\mathrm{H}$ & 1454 & Asymetric deformation vibrations \\
\hline $\mathrm{C}-\mathrm{O}$ & $1180-1046$ & Tension vibration \\
\hline $\mathrm{C}-\mathrm{O} ; \mathrm{C}-\mathrm{C}$ & $1263-1376$ & Out-of-plane deformation vibration \\
\hline
\end{tabular}

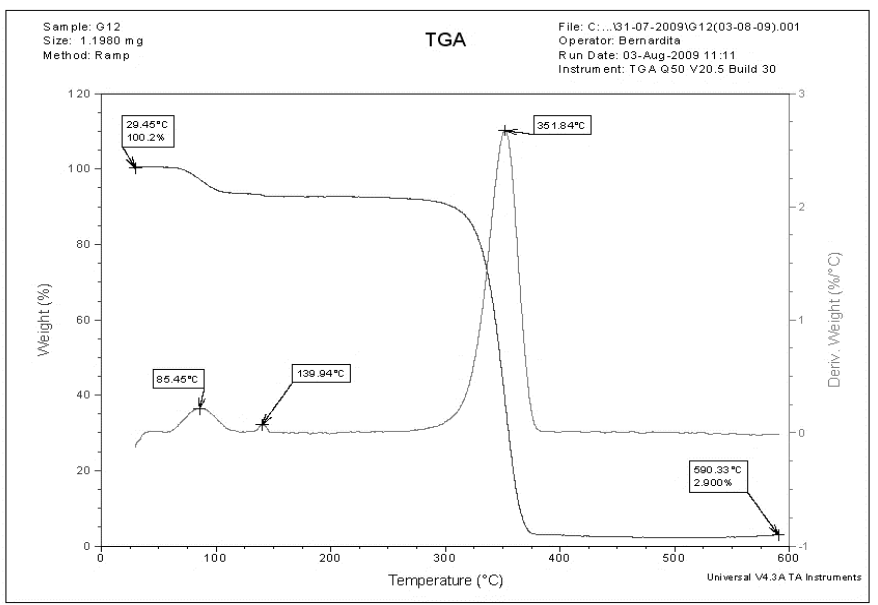

Figure 8. TGA of Polylactic acid.

In the figure we note that at $29^{\circ} \mathrm{C}$ begins the loss of mass and at $85^{\circ} \mathrm{C}$ there is a loss of approximately $5 \%$ corresponding to the water that possesses the sample, then at $139^{\circ} \mathrm{C}$ there is approximately a loss of $10 \%$ mass and at $351{ }^{\circ} \mathrm{C}$ there is a large loss of mass, in which about $60 \%$ is lost due to the decomposition of the substance.

\section{Preparation of tube-shaped biomaterials}

The materials were prepared using different percentages of Calcium Glutamate and Polylactic Acid, obtaining 7 types of tubes, which can be seen in the following photographs.

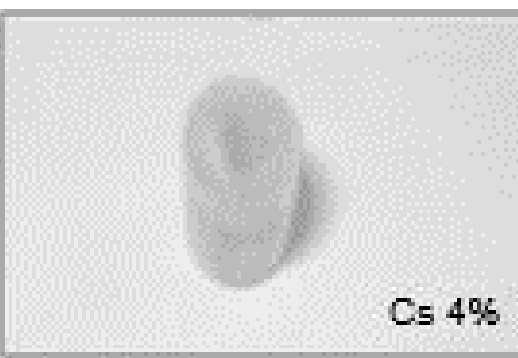

Figure 9. Cs $4 \%$

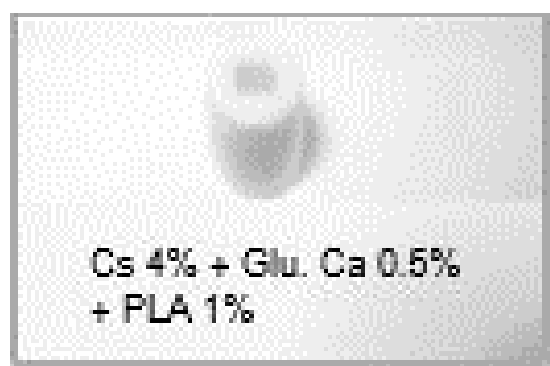

Figure 11. Cs $4 \%$ + Glu.Ca $0.5 \%$ + PLA $1 \%$

Figure 10. Cs $4 \%+$ Glu.Ca $0.5 \%$

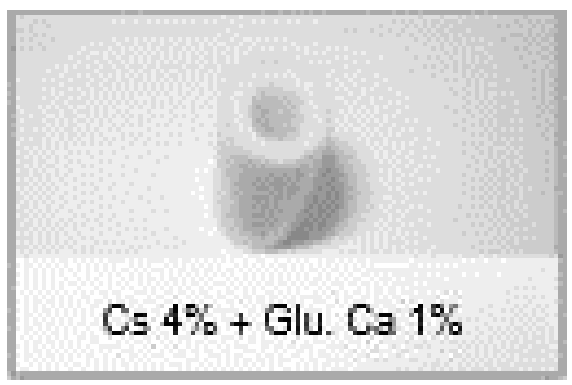

Figure 13. Cs $4 \%$ + Glu.Ca $1 \%$

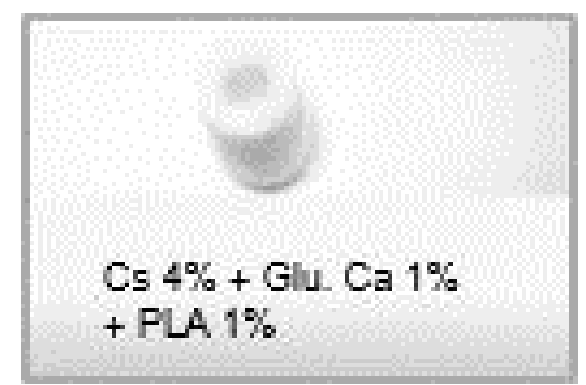

Figure 14. Cs 4\% + Glu.Ca 1\% + PLA $1 \%$

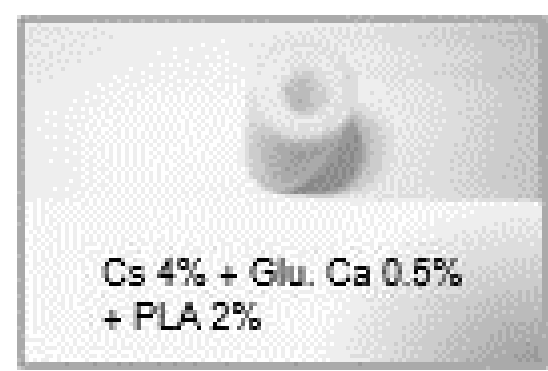

Figure 12. Cs $4 \%+$ Glu.Ca $0.5 \%$ + PLA $2 \%$

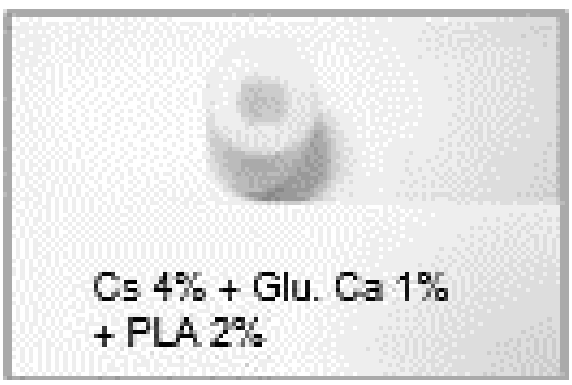

Figure 15. Cs $4 \%+$ Glu.Ca $1 \%+$ PLA $2 \%$ 


\section{FTIR spectroscopy of biomaterials}

Below are the FTIRs obtained, showing that of a material corresponding to that of Cs $4 \%+$ Glu. Ca $1 \%+$ PLA $2 \%$ and also the spectra ordered in relation to the percentage of additive and polylactic acid, in order to be able to compare them. The images are presented in the following order.

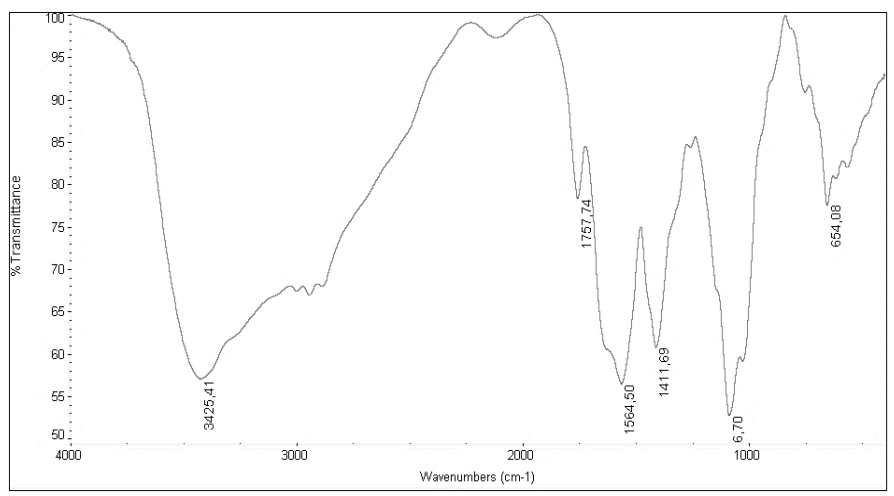

Figure 16. FTIR spectrum of biomaterial Cs $4 \%+$ Glu. Ca 1\% + PLA $2 \%$.

In this spectrum you can observe the characteristic absorption bands of the chitosan, where at $3425 \mathrm{~cm}^{-1}$ the group $\mathrm{O}-\mathrm{H}$ and $\mathrm{N}-\mathrm{H}$ appear and at $1564 \mathrm{~cm}^{-1}$ $\mathrm{NH}_{2}$ group appears. It can also be observed that at $1757 \mathrm{~cm}^{-1}$ the group $\mathrm{C}-\mathrm{O}$ of an ester appears, indicating the presence of polylactic acid in the material, as well as the presence of calcium glutamate, appearing at $1411 \mathrm{~cm}^{-1}$ the group $\left(\mathrm{COO}^{-}\right)$ compound.

The following spectra are ordered in relation to the amount of additive and the amount of polylactic acid used, for comparison purposes. The images are shown below:

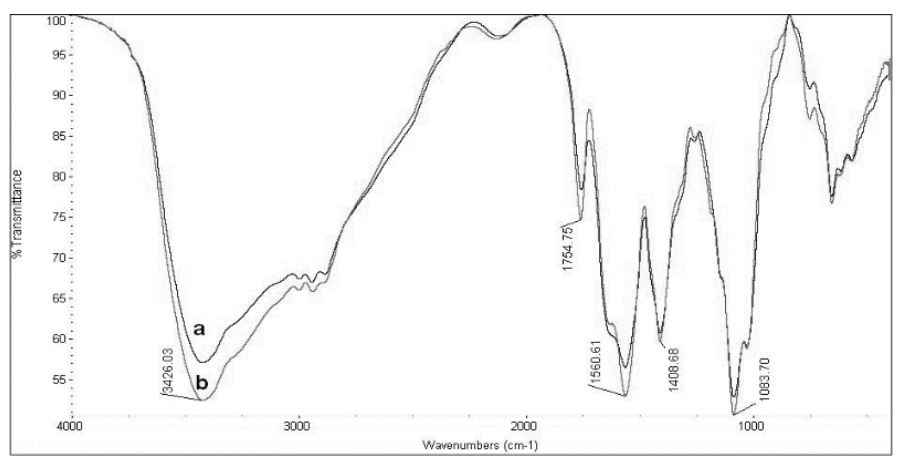

Figure 17. FTIR spectra of a) Cs $4 \%$ + Glu. Ca $0,5 \%$ + PLA $2 \%$ and b) Cs $4 \%+$ Glu. Ca $1 \%+$ PLA $2 \%$.

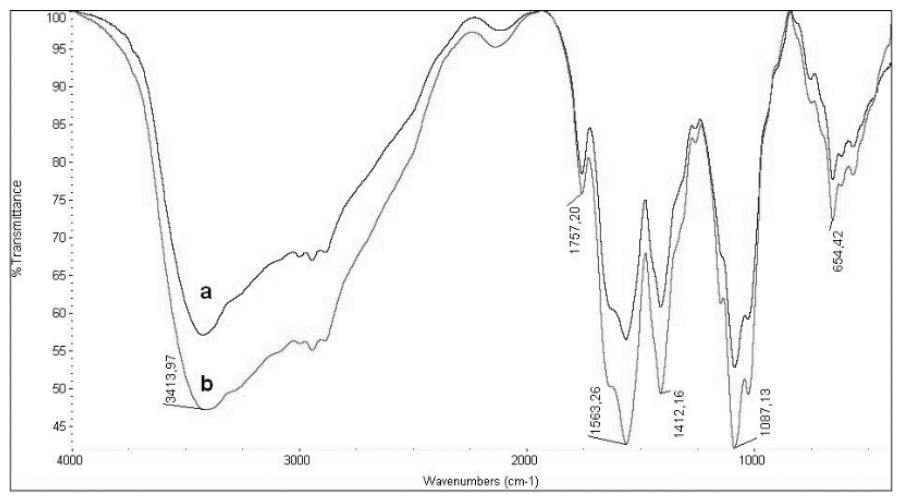

Figure 18. FTIR spectra of a) Cs $4 \%+$ Glu. Ca $1 \%+$ PLA $1 \%$ and b) Cs $4 \%+$ Glu. Ca $1 \%+$ PLA $2 \%$.

Both in Fig.17 as in Fig. 18 it is observed that the materials have the characteristic bands of the species discussed above, appearing between 1408$1412 \mathrm{~cm}^{-1}$ the group $(\mathrm{COO})^{-}$corresponding to Glu. $\mathrm{Ca}$ and the spectrum represented by the letter (b) shows us the increase in bands as the amount of additive and PLA increases.

\section{Thermogravimetric Analysis (TGA)}

This analysis is intended to demonstrate the behavior of the materials obtained, when they are subjected to a temperature program. The following are the thermograms for the different types of biomaterials:

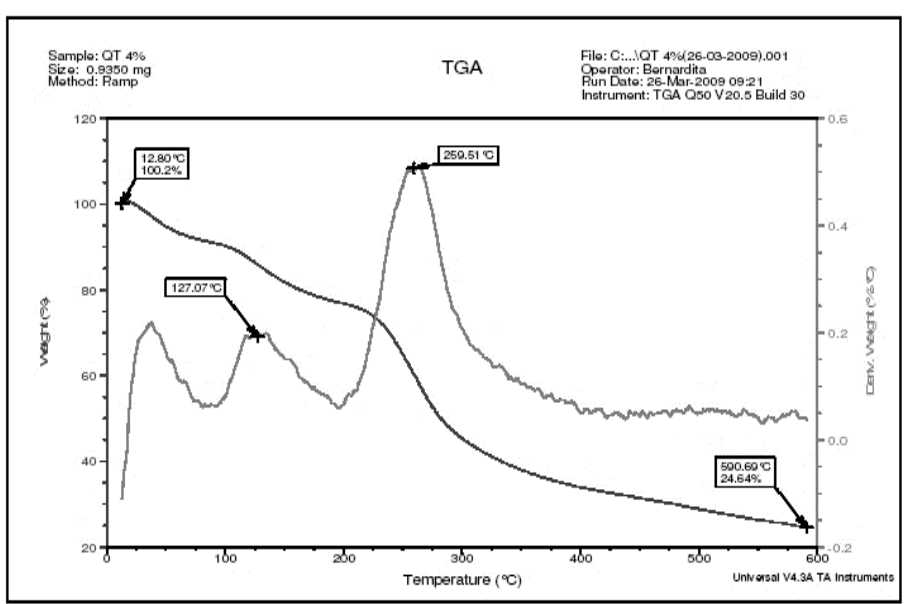

Figure 19. TGA of biomaterial Cs $4 \% \mathrm{w} / \mathrm{v}$.

In the Fig. 19 it is observed that at $13^{\circ} \mathrm{C}$ the mass decline begins and at $127^{\circ} \mathrm{C}$ approximately $20 \%$ mass corresponding to the hydration water of the sample has already been lost, then there is a large loss of mass at $250^{\circ} \mathrm{C}$ in which about $40 \%$ mass is lost by decomposition and depolymerization.

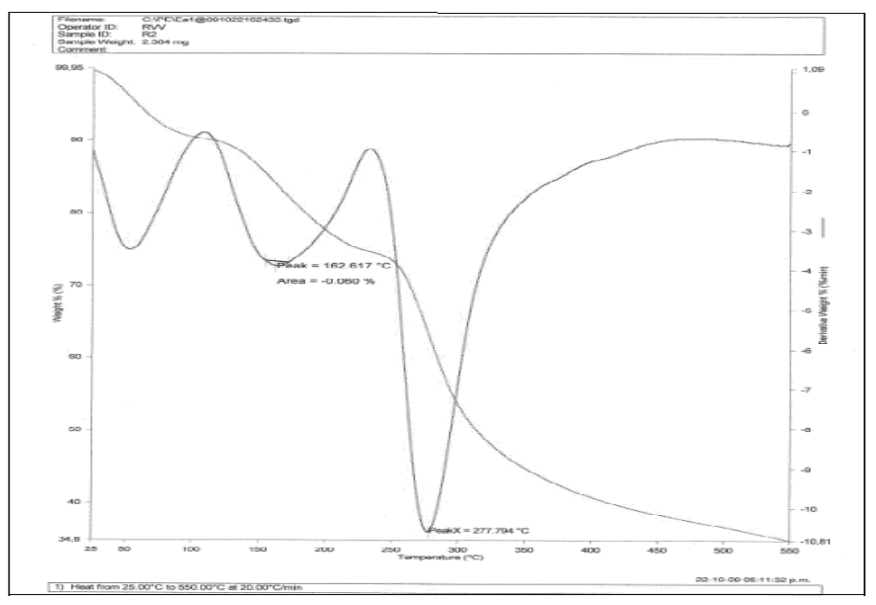

Figure 20. TGA of Biomaterial Cs $4 \%+$ Glu Ca $0.5 \%$.

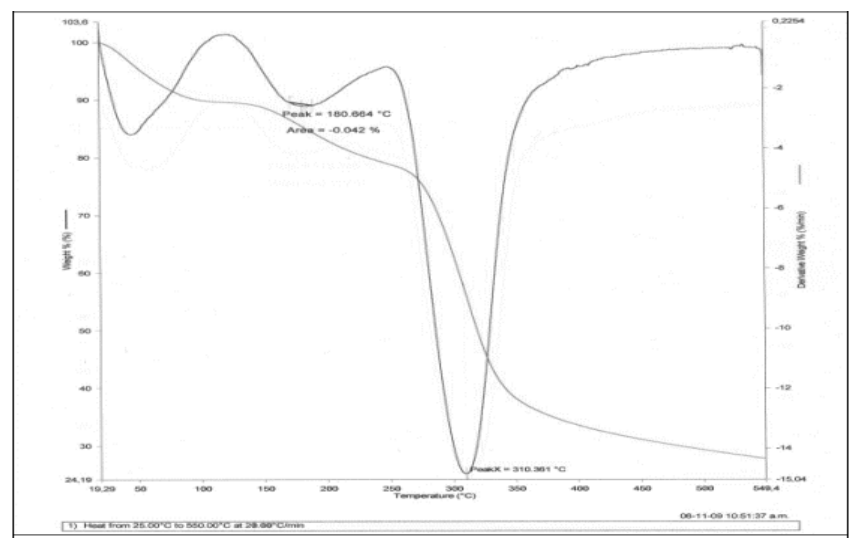

Figure 21. TGA of biomaterial Cs $4 \%+$ Glu. Ca $0.5 \%$ + PLA $1 \%$. 


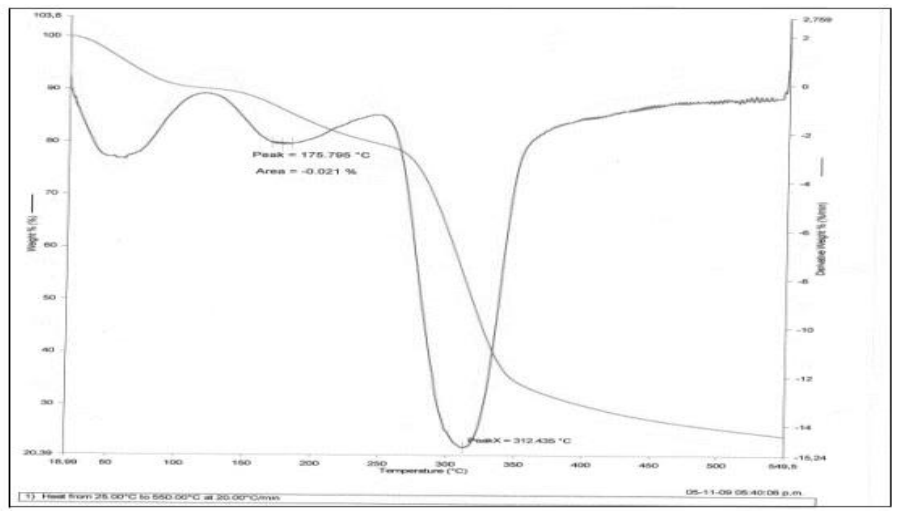

Figure 22. TGA of biomaterial Cs $4 \%+$ Glu. Ca $0.5 \%+$ PLA $2 \%$.

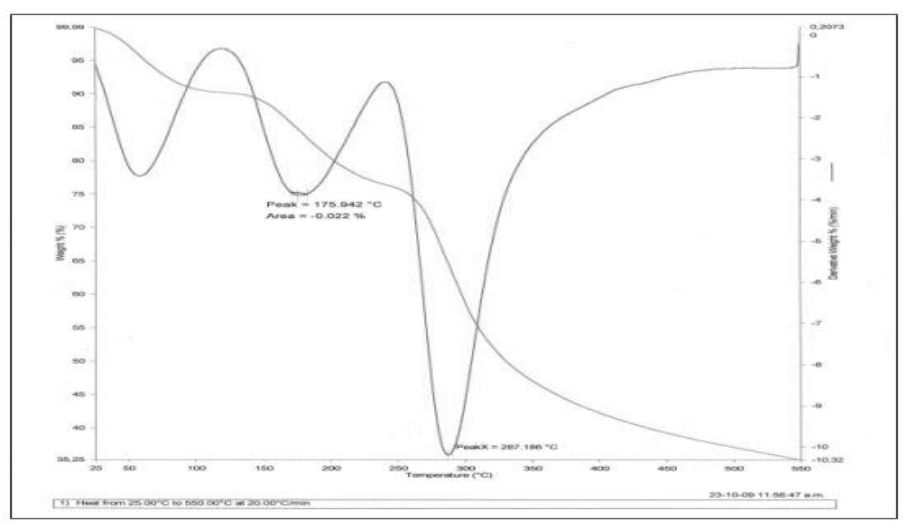

Figure 23. TGA of biomaterial Cs $4 \%+$ Glu. Ca $1 \%$.

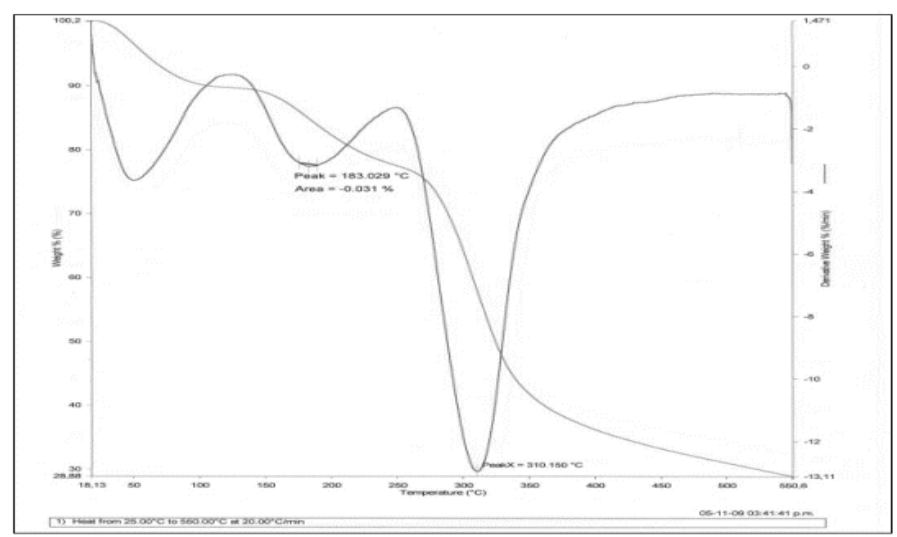

Figure 24. TGA of biomaterial Cs $4 \%+$ Glu. Ca $1 \%+$ PLA $1 \%$.

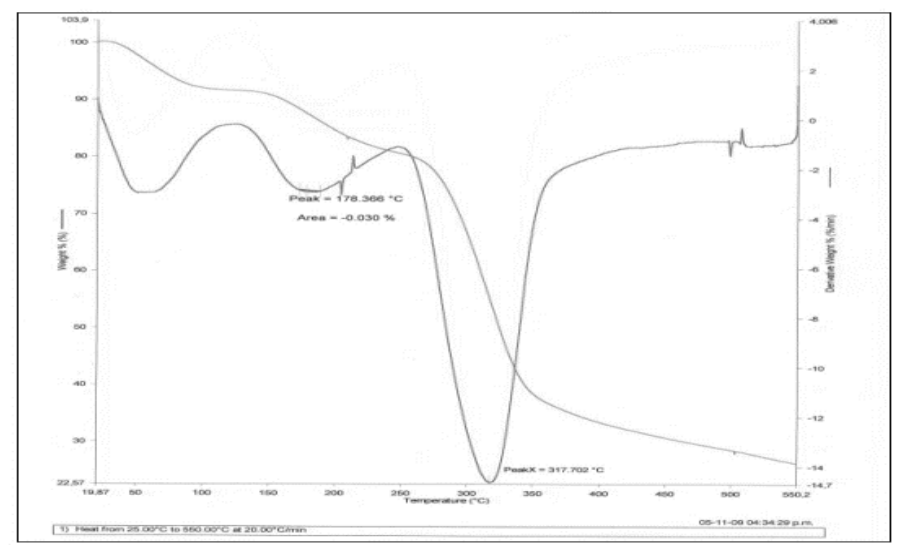

Figure 25. TGA of biomaterial Cs $4 \%+$ Glu. Ca $1 \%+$ PLA $2 \%$.
The following table shows the decomposition temperatures of the different biomaterials obtained.

Table 6. Most significant temperatures in the mass loss of biomaterials.

\begin{tabular}{|l|c|c|}
\hline \multicolumn{1}{|c|}{ Materials } & T1 $\left({ }^{\circ} \mathbf{C}\right)$ & T2 $\left({ }^{\circ} \mathbf{C}\right)$ \\
\hline Cs $4 \%$ + Glu. Ca $0.5 \%$ & 162 & 277 \\
\hline Cs 4\% + Glu. Ca $0.5 \%+$ PLA $1 \%$ & 180 & 310 \\
\hline Cs 4\% + Glu. Ca $0.5 \%+$ PLA $2 \%$ & 175 & 312 \\
\hline Cs 4\% + Glu. Ca 1\% & 175 & 287 \\
\hline Cs 4\% + Glu. Ca 1\% + PLA 1\% & 183 & 310 \\
\hline Cs 4\% + Glu. Ca 1\% + PLA $2 \%$ & 178 & 317 \\
\hline
\end{tabular}

In the figures presented above and the temperature data shown in Table $\mathrm{N}^{\circ} 6$, it can be established that for all biomaterials mass loss starts at approximately $50^{\circ} \mathrm{C}$, they have two significant mass losses at almost the same temperature. In the first $\left(\mathrm{T}_{1}\right)$ one $25 \%$ mass and the second $\left(\mathrm{T}_{2}\right)$ where a large mass loss of about $40 \%$ occurs.

\section{Atomic Absorption Spectroscopy}

Table 7. Calibration Curve for Calcium $(\lambda=422.7 \mathrm{~nm})$.

\begin{tabular}{|c|c|}
\hline Concentration $(\mathbf{m g} / \mathbf{L})$ & Absorbance \\
\hline 0.000 & 0.000 \\
\hline 1.000 & 0.351 \\
\hline 2.000 & 0.683 \\
\hline 3.000 & 0.989 \\
\hline 4.000 & 1.262 \\
\hline 5.000 & 1.645 \\
\hline
\end{tabular}

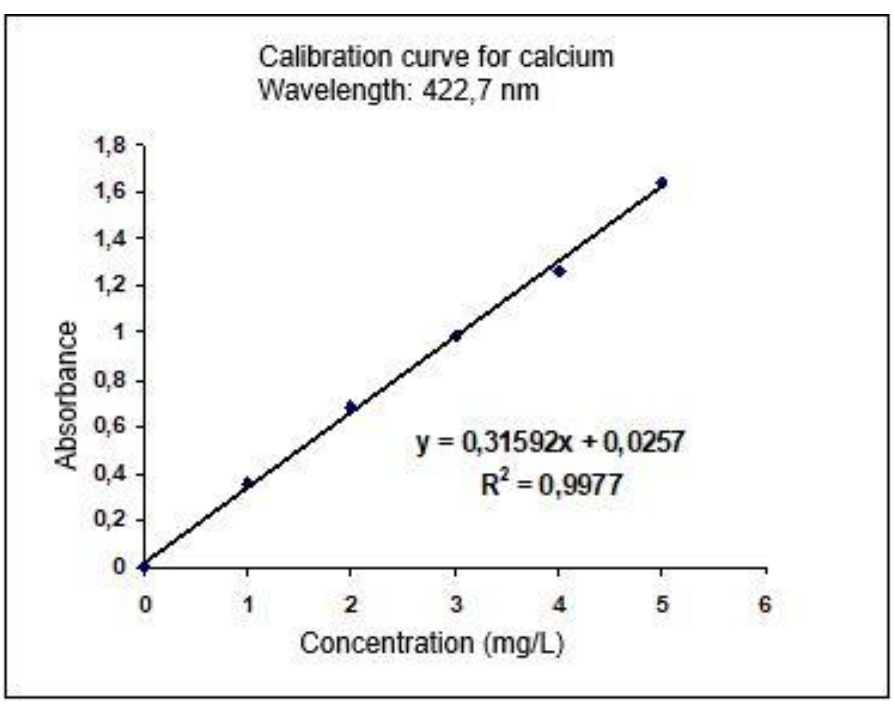

Figure 26. Calibration curve for Calcium.

\begin{tabular}{|l|c|c|c|c|c|}
\hline \multicolumn{1}{|c|}{ Materials } & $\begin{array}{c}\text { Mass } \\
(+/-\mathbf{0 . 1 m g})\end{array}$ & Abs & $\begin{array}{c}\text { Dilution } \\
\text { factor }\end{array}$ & $\begin{array}{c}\text { Corrected } \\
\text { concent. (mg/L) }\end{array}$ & $\% \mathbf{C a}$ \\
\hline Cs 4\% + Glu. Ca 0.5\% & 50.5 & 0.862 & 5 & 13.24 & 1.3 \\
\hline Cs 4\% + Glu. Ca 0.5\% + PLA 1\% & 50.1 & 0.778 & 5 & 11.91 & 1.1 \\
\hline Cs 4\% + Glu. Ca 0.5\% + PLA 2\% & 50.1 & 0.634 & 5 & 9.63 & 0.9 \\
\hline Cs 4\% + Glu. Ca 1\% & 50.2 & 0.817 & 10 & 25.05 & 2.5 \\
\hline Cs 4\% + Glu. Ca 1\% + PLA 1\% & 50.4 & 1.114 & 5 & 17.22 & 1.7 \\
\hline Cs 4\% + Glu. Ca 1\% + PLA 2\% & 50.1 & 0.994 & 5 & 15.33 & 1.5 \\
\hline
\end{tabular}


Scanning electron microscopy of the various biomaterials obtained.

\section{Microphotographs of Biomaterials.}

Below are the surfaces of the materials, in which it is appreciated that some have more defined pores than others.

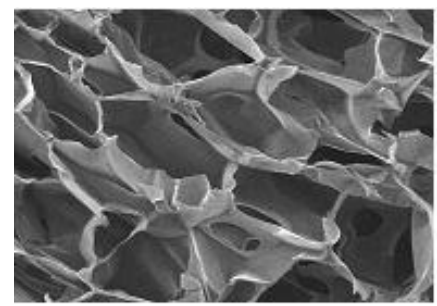

Figure 27. SEM of Cs $4 \%$

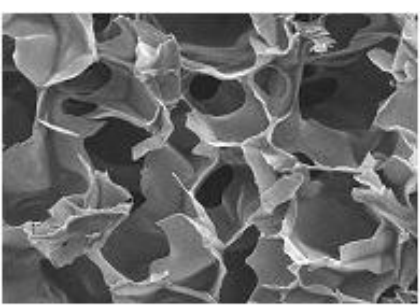

Figure 29. SEM of Cs $4 \%+$ Glu. Ca $1 \%$

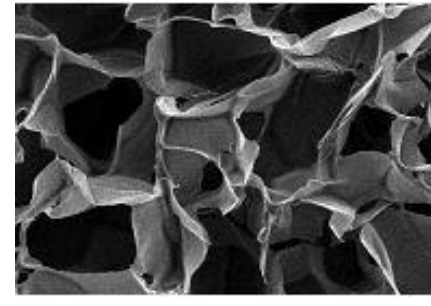

Figure 31. SEM of Cs $4 \%+$ Glu. Ca $1 \%+$ PLA $1 \%$

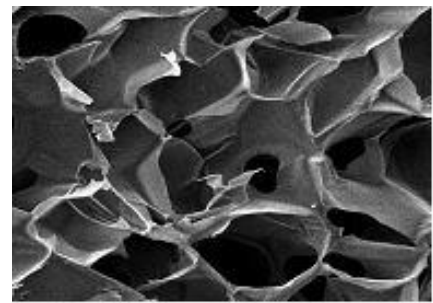

Figure 33. SEM of Cs $4 \%+$ Glu. Ca $1 \%+$ PLA $2 \%$

The following table shows the pore sizes presented by these materials.

Table 9. Average pore size of the different biomaterials.

\begin{tabular}{|l|c|}
\hline \multicolumn{1}{|c|}{ Materials } & Average pore size $(\boldsymbol{\mu m})$ \\
\hline Cs $4 \%$ & 163 \\
\hline Cs $4 \%+$ Glu. Ca $0.5 \%$ & 139 \\
\hline Cs $4 \%+$ Glu. Ca $0.5 \%+$ PLA $1 \%$ & 136 \\
\hline Cs $4 \%+$ Glu. Ca $0.5 \%+$ PLA $2 \%$ & 118 \\
\hline Cs $4 \%+$ Glu. Ca $1 \%$ & 135 \\
\hline Cs $4 \%+$ Glu. Ca $1 \%+$ PLA $1 \%$ & 128 \\
\hline Cs $4 \%+$ Glu. Ca $1 \%+$ PLA $2 \%$ & 124 \\
\hline
\end{tabular}

It can be observed that the pore size decreases as the amount of Calcium Glutamate increases, the same behavior is observed as the percentage of PLA increases.

\section{Solubility tests}

Table 10. Data for solubility tests.

\begin{tabular}{|l|c|c|c|}
\hline \multicolumn{1}{|c|}{ Samples } & $\begin{array}{c}\text { Initial mass } \\
(+/-\mathbf{0 . 1 m g})\end{array}$ & $\begin{array}{c}\text { Final mass } \\
(+/-\mathbf{0 . 1 m g})\end{array}$ & $\begin{array}{c}\% \text { Solubilized } \\
\text { mass }\end{array}$ \\
\hline Cs 4\% & 36.2 & 29.5 & 18.5 \\
\hline Cs 4\% + Glu. Ca 0.5\% & 37.4 & 31.3 & 16.3 \\
\hline Cs 4\% + Glu. Ca 0.5\% + PLA 1\% & 41.6 & 36.3 & 12.7 \\
\hline Cs 4\% + Glu. Ca 0.5\% + PLA 2\% & 48.7 & 43.1 & 11.5 \\
\hline Cs 4\% + Glu. Ca 1\% & 40.1 & 33.8 & 15.7 \\
\hline Cs 4\% + Glu. Ca 1\%+ PLA 1\% & 47.6 & 42.7 & 10.3 \\
\hline Cs 4\% + Glu. Ca 1\% + PLA 2\% & 54.8 & 50.2 & 8.4 \\
\hline
\end{tabular}

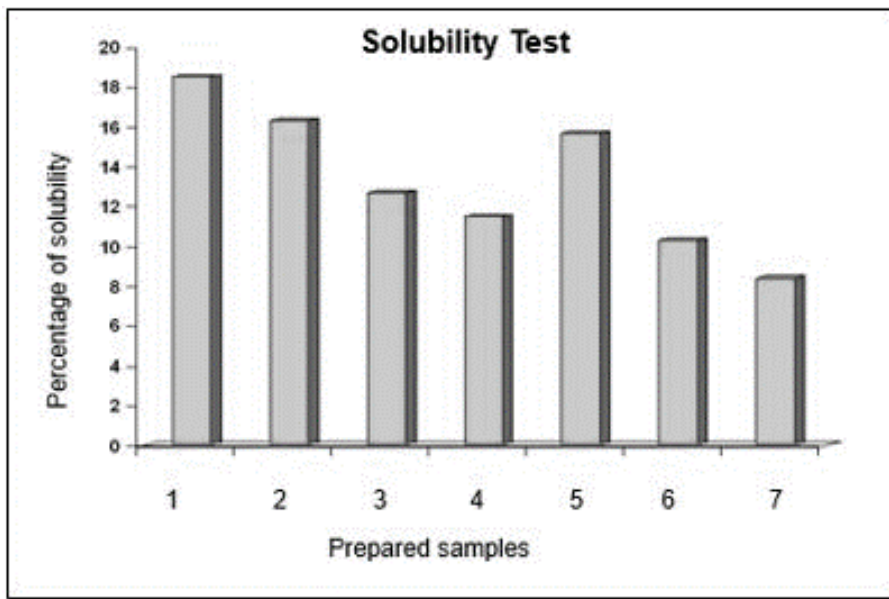

Figure 34. Solubility test chart for different types of biomaterials.

From the data obtained through the solubility test, we can establish that materials with Glu. Ca causes a decrease in solubility, but this property improves even more, in those prostheses that have the coating with PLA. According to these results, the material that was less soluble corresponds to Cs $4 \%+\mathrm{Glu}$. Ca $1 \%+$ PLA $2 \%$ presenting $8.4 \%$ solubilized mass.

\section{Mechanical Properties}

Table 11. Data for the analysis of mechanical properties.

\begin{tabular}{|l|c|c|c|}
\hline Materials & $\begin{array}{c}\text { Maximum } \\
\text { Strength }\end{array}$ & $\begin{array}{c}\text { Compression } \\
\text { Resistance } \\
\text { (MPa) }\end{array}$ & $\begin{array}{c}\text { Elasticity } \\
\text { Modulus } \\
\text { (MPa) }\end{array}$ \\
\hline Cs 4\% & 0.05 & 0.27 & 1.04 \\
\hline Cs 4\% + Glu. Ca 0.5\% & 0.02 & 0.59 & 3.58 \\
\hline Cs 4\% + Glu. Ca 0.5\% + PLA 1\% & 0.04 & 0.76 & 6.55 \\
\hline Cs 4\% + Glu. Ca 0.5\% + PLA 2\% & 0.02 & 0.83 & 11.02 \\
\hline Cs 4\% + Glu. Ca 1\% & 0.03 & 0.88 & 15.00 \\
\hline Cs 4\% + Glu. Ca 1\% + PLA 1\% & 0.03 & 0.98 & 18.64 \\
\hline Cs 4\% + Glu. Ca 1\% + PLA 2\% & 0.02 & 1.14 & 25.02 \\
\hline
\end{tabular}

From the analysis carried out to the materials we can see that the samples are more resistant with the addition of additive and in turn this is enhanced with the polylactic coating, making these materials harder and therefore less flexible. 
The following graphs show the influence on the mechanical properties that these materials present when the additive concentration is modified.

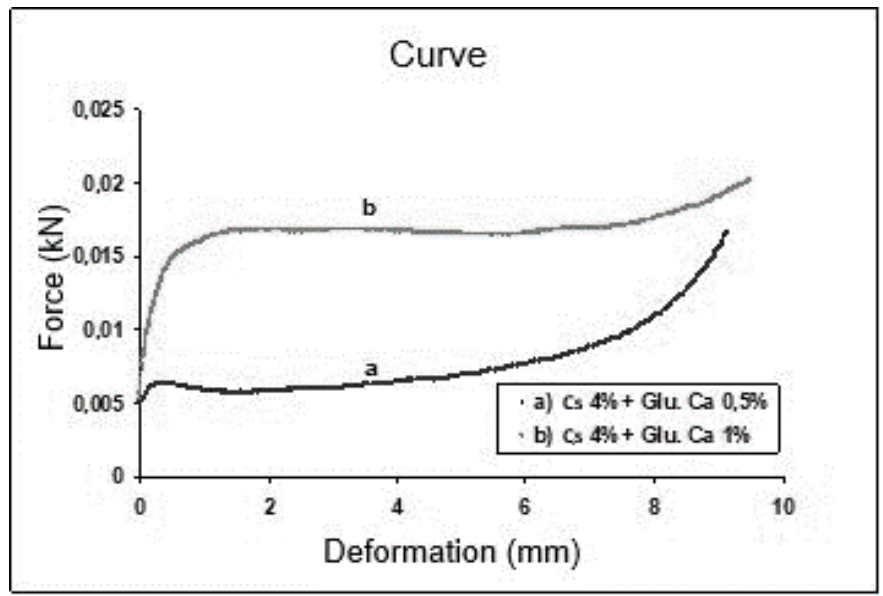

Figure 35. Influence of the additive on the mechanical properties of biomaterial.

In the following cases we can establish that the increase in additive concentration helps to improve the resistance to deformation of the material for a certain time, but then by continuing to apply force it deforms, a phenomenon known as elastic deformation of the material.

The following graphs show the influence on the mechanical properties that these materials present, when the additive concentration is kept constant but varies in the concentration of PLA.

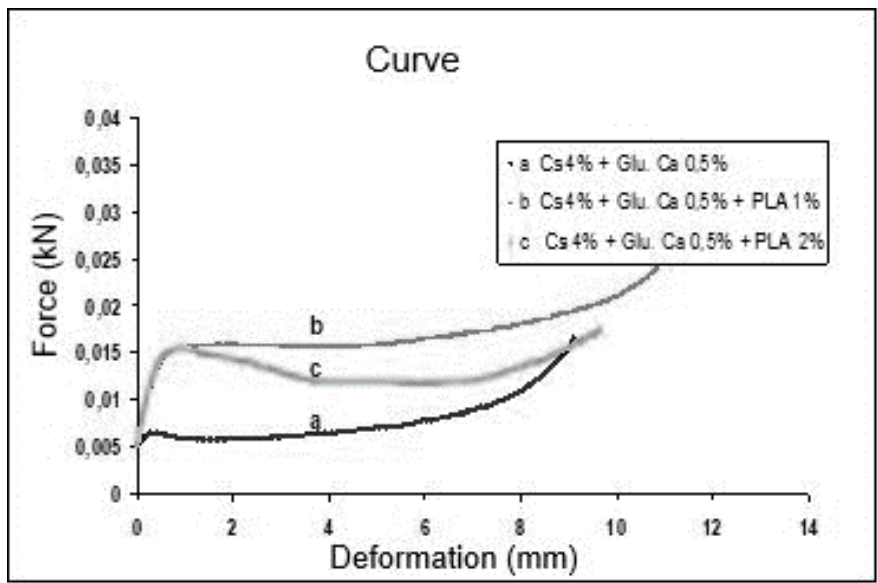

Figure 36. Influence of the PLA on the mechanical properties of biomaterials.

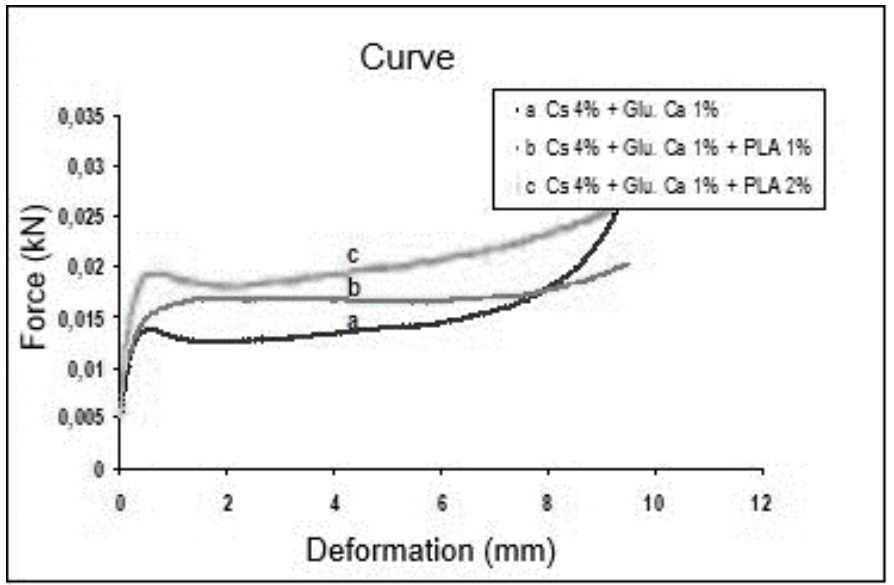

Figure 37. Influence of the PLA on the mechanical properties of biomaterials
We can see that in both cases the materials have some resistance to deformation and at the same time this resistance becomes greater as the amount of PLA increases, allowing us to establish that those materials coated with PLA are harder and less flexible.

\section{CONCLUSIONS}

Seven types of chitosan biomaterials were prepared using different percentages of calcium glutamate and polylactic acid, the latter to reinforce the structure of biomaterials.

The different biomaterials are successfully characterized with traditional analysis techniques.

In the development of biomaterials it is strongly stated that those who were coated with a higher concentration of polylactic acid, have better properties than uncovered materials, giving them greater resistance and preventing them from deteriorating easily in physiological environment.

The biomaterial composed of the mixture of Cs $4 \%+$ Glu. Ca $1 \%+$ PLA $2 \%$, makes us assume that it will allow us to solve one of the biggest drawbacks presented by these materials, which corresponds to the collapse of this due to the great solubility that it has in biological environment, since said material has a low solubility when performing this test in a simulated medium with physiological serum.

Another important aspect to evaluate is their thermal stability, through the analyses carried out by TGA, show us that the materials are stable up to about $160^{\circ} \mathrm{C}$, making them resistant and applicable to the human body, since the temperature of the human body fluctuates between 36 to $37^{\circ} \mathrm{C}$.

The pores of the different biomaterials are defined and decrease as the amount of additive increases, the same behavior is observed as the percentage of polylactic acid increases. However, this trend does not prevent its application in the repair of peripheral nerves.

\section{ACKNOWLEDGEMENTS}

The authors would like to thank the financial aid of Innova BioBio Grant 8PCS1-260.

\section{REFERENCES}

1. Afifi AK. Neuroanatomía functional. Texto y Atlas. México (DF): McGrawHill Interamericana, (1999).

2. Catala M, Teillet M -A, De Robertis E M , Le Douarin N M . A spinal cord fate map in the avian embryo: While regressing, Hensen's node lays down the notochord and floor plate thus joining the spinal cord lateral walls. Development, 122:2599-2610, (1996).

3. Moury J D , Schoenwolf G C . Cooperative model of epithelial shaping and bending during avian neurulation: Autonomous movements of the neural plate, autonomous movements of the epidermis, and interactions in the neural plate/epidermis transition zone. Dev. Dyn, 204: 323-337, (1995).

4. Smith J L , Schoenwolf G C . Neurulation: Coming to closure. Trends Neurosci, 11:510-517, (1997).

5. Vassilis EK, Rajiv RR. Cell death and diseases of the nervous system. Totowa, Nueva Jersey: Humana Press, (1986).

6. Garbay B, Heape, AM, Sargeil, F, Cassage C. Myelin synthesis in the peripheral nervous system. Prog Neurobiol, 61:267-304, (2000).

7. Smith KS, Kapoor R, Hall SM, Davies M. Electrically Active Axons Degenerate When Exposed to Nitric Oxide. Ann Neurol, 49:470-476, (2001).

8. Araki T, Milbrandt J. Ninjurin, A novel adhesion molecule, is induced by nerve injury and promotes axonal growth. Neuron, 17:353-361, (1996).

9. Perry V, Luner E, Brown M. Evidence that three rate of Wallerian degeneration is controlled by a single autosomal dominant gene. Eur J Neurosci, 2:402-408, (1990).

10. Evanthia Nikolopoulou, Gabriel L. Galea, Ana Rolo, Nicholas D. E. Greene, Andrew J. CoppNeural tube closure: cellular, molecular and biomechanical mechanisms. Development, 144: 552-566; (2017). doi: 10.1242/dev.145904

11. Chaudry V, Glass J, Friffin J. Wallerian degeneration in peripheral nerve disease. Neurol Clin, 10:613-627, (1992).

12. Dumitru, D. Reaction of the peripheral nervous system to injury. In electrodiagnostic medicine. Filadelfia: Ed Hanley-Belfus Inc, (1994). 
13. Weiss P. The technology of nerve regeneration. Sutureless tubulation and related methods of nerve repair. Neurosurgery, 1:400-450, (1944).

14. Ayala H. Estudio Experimental en la cirugía de los nervios periféricos. Rev Ortop Traum, 2:3-14, (1997).

15. Sulaiman ARO, Gordon T. Effects of Short- and Long-Term Schwann Cell. Denervation on Peripheral Nerve Regeneration, Myelination, and Size. Glia, 32: 234-246, (2000).

16. Barakat W. The role of thyroid hormones and their receptors in peripheral nerve regeneration. J Neurobiol, 40:541, (1999).
17. Dahlin LB., Lundborg G. Use of tubes in peripheral nerve repair. Neurosurgery Clinics of North America, 1:341-352, (2001).

18. G. Sundback C, Hadlock T, Cheney M, Vacanti J. Biomaterials; 24: $819-$ $830,(2003)$

19. Benavides-Cuellar, MA. Quitina-Quitosana. Los polímeros del futuro. División de comunicaciones, Servicio Nacional de Aprendizaje SENA, Centro de Desarrollo Tecnológico y Asistencia Técnica a la Industria. Santiago de Cali, (2002).

20. Aguado A, David S, Richardson P, Bray G. Axonal elongation in peripheral and central nervous system transplants. Adv Cell Neurobiol, 3:215, (1982). 